$18^{\text {th }}$ International Conference on Environmental Degradation in Nuclear Power Systems - Water Reactors Portland, Oregon, USA, 13-17 August 2017

\title{
Oxidation and SCC initiation studies of Type 304L SS in PWR primary water
}

\author{
F. Scenini ${ }^{1}$, J. Lindsay ${ }^{1}$, Litao Chang $^{1}$, Y.L. Wang ${ }^{1}$, M.G. Burke ${ }^{1}$, S. Lozano-Perez ${ }^{2}$, G. Pimentel ${ }^{2}$, D. Tice ${ }^{3}$, K. \\ Mottershead ${ }^{3}$, V. Addepalli ${ }^{3}$ \\ ${ }^{1}$ University of Manchester, Material Performance Centre, Manchester, UK \\ 2 University of Oxford, Department of Materials, Parks Road, Oxford, OX1 3PH, UK \\ ${ }^{3}$ AMEC Foster Wheeler, Walton House, Birchwood Park, Birchwood Warrington, Cheshire, WA3 6GA, UK
}

\section{Abstract}

Slow strain rate tensile (SSRT) tests were conducted on conventional and tapered samples manufactured from forged Type 304L stainless steel to assess the stress corrosion cracking (SCC) behaviour in simulated PWR primary water. Several testing and microstructural parameters were investigated in order to explore the conditions under which crack initiation might occur. Surface preparation appeared to play a very important role on SCC initiation whereby the machined surfaces were the least susceptible to SCC initiation whilst oxide polishing suspension (OPS) polished surfaces were more susceptible. On the machined surfaces the cracks were always transgranular (TG) in nature and associated with the machining marks. Conversely, on fine polished surfaces with oxide polishing suspension the crack morphology was mainly intergranular in nature, although minor transgranular cracking was observed. The regions in the proximity of the $\delta$ ferrite/austenite interface were shown to be very susceptible to SCC initiation especially on the OPS polished surfaces and this was attributed to the strain localization upon dynamic deformation. Furthermore, intragranular inclusions appeared to dissolve and act as initiation sites for transgranular cracking to occur. The roles of strain rate, dynamic deformation and microstructure on the initiation of SCC are also discussed.

\section{Key words:}

Oxidation, stress corrosion cracking (SCC) initiation, slow strain rate test (SSRT), 304L stainless steel.

\section{Introduction}

Austenitic stainless steels, such as Types 304 and 316, have been widely used in the core internals and auxiliary circuits of the pressurized water reactors (PWR) [1-3]. Despite the very good corrosion resistance in aqueous environment, these materials can suffer from environmentally-assisted degradation problems during the very long exposure to high temperature water, especially in poorly refreshed regions where the water chemistry deviates from the nominal conditions. However, in the last decade, a number cases of intergranular SCC have been also identified in the cold-worked areas of the non-sensitized austenitic stainless steel components of both French and Japanese PWR power plants [1, 4-6].

SCC is characterized by a long incubation time prior to the early stage of slow propagation and followed by relatively fast propagation [7, 8]. Based on the SCC statistics identified in the French PWRs by Couvant et al. [1], most of the cases were identified after a period of at least of 50000 hours. Literature results also indicate that the water chemistry [9-11], testing temperature [12], degree and paths of pre-strain $[9,10,13,14]$ and surface finish [15-17] and heat treatment are the main factors that influence SCC.

Furthermore, when austenitic stainless steels are exposed to high temperature water, a double layer structured oxide layer forms, which consists of a fine grained, compact, and chromium-rich inner oxide layer 
and a non-uniform, coarse grained and iron-rich outer layer. Result of Kruska et al. and Lozano-Perez suggest that the oxidation which preferentially occurs along the grain boundaries and slip bands could be one of the possible reasons for the occurrence of SCC. Results of Cisse et al. [2], Miura et al. [18] and Yonezawa et al. indicate that the deformation in the surface introduced during component manufacturing enhances the elemental diffusion and influences the oxidation and SCC initiation. Recent analysis on components removed from boiling water reactor also highlighted the importance of deformation of the surface and the feature of the surface to SCC initiation $[18,19]$. The surface defects originated from manufacturing can also act as a location where crack initiation pre-cursor can occur also because the local concentration of aggressive ion formation is promoted by oxygen in BWRs or by heat flux in PWRs (e.g. in the pressurizer) [20].

Despite the large research effort, SCC initiation of austenitic stainless steels in PWR water environment is still relatively poorly understood. Therefore, the aim of the current paper is to present some of the results from an ongoing collaborative project with AMEC Foster Wheeler and the University of Oxford which is aimed at improving understanding of the conditions under which crack initiation and subsequent development of stress corrosion cracks in stainless steels in PWR primary coolant might be possible. The effect of plastic deformation, strain rate, surface preparation and microstructure on SCC initiation of 304 SS are reported and discussed.

\section{Experimental details}

\subsection{Material}

The material used for this work is a type $304 \mathrm{~L}$ austenitic stainless steel whose composition is reported in Table 1. The low nickel content of the material appears to be slightly out of specification and is likely contributing to the high ferrite content that was identified in the alloy. The material was a $65 \mathrm{~mm}$ thick plate which received a solution annealing treatment in the temperature range $1050-1100^{\circ} \mathrm{C}$ by the manufacturing company. Subsequently, the material was forged to a $20 \%$ reduction in the temperature window $360-170^{\circ} \mathrm{C}$ to simulate the heat shrinkage that can occur in the heat affected zone of a weld. The same material was also used for the work reported in two other papers presented in this conference [21, 22].

Table 1: Chemical composition of tested materials (wt.\%)

\begin{tabular}{|c|c|c|c|c|c|c|c|c|}
\hline $\mathrm{Cr}$ & $\mathrm{Ni}$ & $\mathrm{C}$ & $\mathrm{Mn}$ & $\mathrm{Mo}$ & $\mathrm{Si}$ & $\mathrm{S}$ & $\mathrm{P}$ & $\mathrm{Fe}$ \\
\hline 18.34 & 7.93 & 0.029 & 1.86 & 0.33 & 0.36 & 0.004 & 0.023 & balance \\
\hline
\end{tabular}

\subsection{Sample geometry and surface preparation}

Two different tensile sample geometries were used: i) conventional geometry, and ii) a tapered gauge section, both of which are shown in Figure 1 below. The conventional samples were $1 \mathrm{~mm}$ thick with a 12 $\mathrm{mm}$ long and $3.5 \mathrm{~mm}$ wide gauge length. The tapered sample was $2.5 \mathrm{~mm}$ thick and its gauge length was also $12 \mathrm{~mm}$ long but varied in width between $4 \mathrm{~mm}$ to $6 \mathrm{~mm}$.
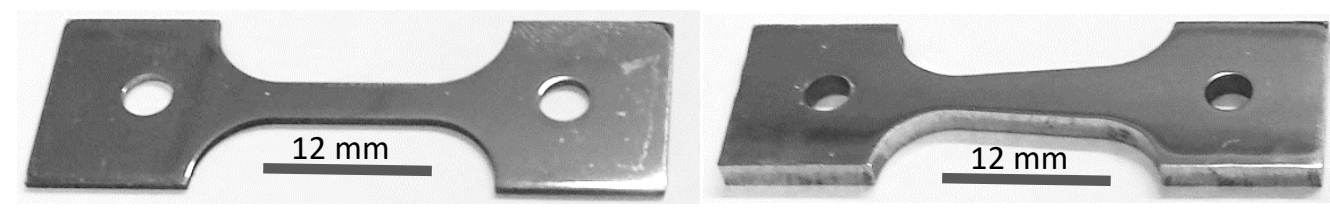

Figure 1 Images of the SSRT sample with conventional gauge (left) and taper geometry (right) used in this study.

All samples were fabricated using electric discharge machining (EDM). The surface damage induced by EDM 
was removed by grinding all the sides of the sample using a 400 grit silicon carbide paper. A total of three surface finishes were investigated, namely i) machining using industrial standard practice, ii) grinding with 600 grit finish and iii) fine polishing to create a reference well-controlled and strain-free surface [23].

The machined samples were tested to investigate plant-relevant surface conditions. The surfaces were machined with a cutting speed $V_{c}=178 \mathrm{~m} / \mathrm{min}$, cutting depth ap $=2.75 \mathrm{~mm}$ and feed speed per tooth $\mathrm{F}_{2}=$ $0.1 \mathrm{~mm} /$ tooth. Afterwards the SSRT sample was extracted using EDM and the specimen surface opposite to the machined surface received and oxide polishing suspension (OPS) finish as reported above for the other samples.

The sample with a 600 grit silicon carbide paper finish was prepared such that the grinding marks were parallel to the loading direction to allow for observation of cracks. The opposite side of the tensile specimen was progressively ground with 600, 800,1200, 2400 and 4000 grit silicon carbide paper. A $3 \mu \mathrm{m}$ and $1 \mu \mathrm{m}$ water based polishing suspension were then used before finishing the surface for a minimum of 30 minutes with a $60 \mathrm{~nm}$ OPS.

\subsection{SCC testing}

In order to investigate the SCC initiation susceptibility of forged 304L stainless steel, slow strain rate tensile (SSRT) test technique was employed in simulated PWR primary water environment to accelerate the crack initiation in these materials. The tests were conducted in a refreshed autoclave loop at $300^{\circ} \mathrm{C}$ in ultrahigh purity water containing $2 \mathrm{ppm}$ of $\mathrm{Li}$ (added as $\mathrm{LiOH}$ ), $3 \mathrm{ppm}$ of dissolved $\mathrm{H}_{2}$ and less than $2 \mathrm{ppb}$ of $\mathrm{O}_{2}$. The samples were strained at a rate of $10^{-6} \mathrm{~s}^{-1}$ until the load had approached $80 \%$ of the yield strength of the samples, thereafter the strain rate was reduced to the desired value until the samples were plastically deformed by $5 \%$. Three different strain rates were used, which ranged from $1 \times 10^{-7} 1 / \mathrm{s}, 2.5 \times 10^{-8} 1 / \mathrm{s}$ and $1 \times 10^{-8} 1 / \mathrm{s}$. After the test, surfaces of the samples were firstly plan view examined and then the samples were longitudinally sectioned and examined.

\subsection{Microstructural characterization}

Microstructural characterisation of the as-received and the post-test specimens was performed using a Zeiss Ultra 55 field emission gun (FEG) scanning electron microscope equipped with an Oxford Instruments Si(Li) EDX spectrometer, EBSD detector and INCA analysis system, and a Zeiss Sigma FEG-SEM equipped with an Oxford Instruments X-max 150 Silicon Drift Detector (SDD) and an EBSD detector with the AZTEC analysis system. Both secondary electron (SE) and backscattered electron (BSE) imaging modes were used to assess the microstructure and extent of cracking in the post-test specimens. EBSD analyses were performed on specimens that had been metallographically prepared with an OPS final polish.

For evaluation of crack depths, cross-section specimens were prepared from the as-tested tensile specimens. Specimens were initially sectioned longitudinally using a Struers Accutom, mounted in conductive resin, ground and polished to a final OPS finish.

\section{$4 \quad$ Results}

\subsection{Baseline materials characterization}

The material was contained a nominal $\delta$-ferrite content of about $1.8 \%$. However, upon examination it was noted that the microstructure was not homogeneous and several bands, which were several hundred microns in extent, were located near in the centre of the forging. Examination of this region indicated that no $\delta$-ferrite was present and this was confirmed by EBSD analysis Figure $2 \mathrm{~b}$. Furthermore, whilst the grain size in the $\delta$-ferrite containing matrix was approximately $35 \mu \mathrm{m}$, a coarser grain structure was observed in the band with no $\delta$-ferrite (Figure 2a). SEM-EDX microanalysis of the bands that contained no $\delta$-ferrite were 
enriched in $\mathrm{Ni}$ and $\mathrm{Mn}$ [22], which would promote the austenite phase stability. Furthermore, in these $\delta$ ferrite free bands an increased proportion of inclusions was observed. A Secondary Electron (SE) image of a typical inclusion, which fractured during the material processing, is shown in Figure 2c. Inclusions were not single phase, but rather an agglomeration of Al-rich oxides, MnS and Ti-rich inclusions. Detailed characterization of these bands and of the inclusions is reported in another paper presented at this conference by the present authors [21].

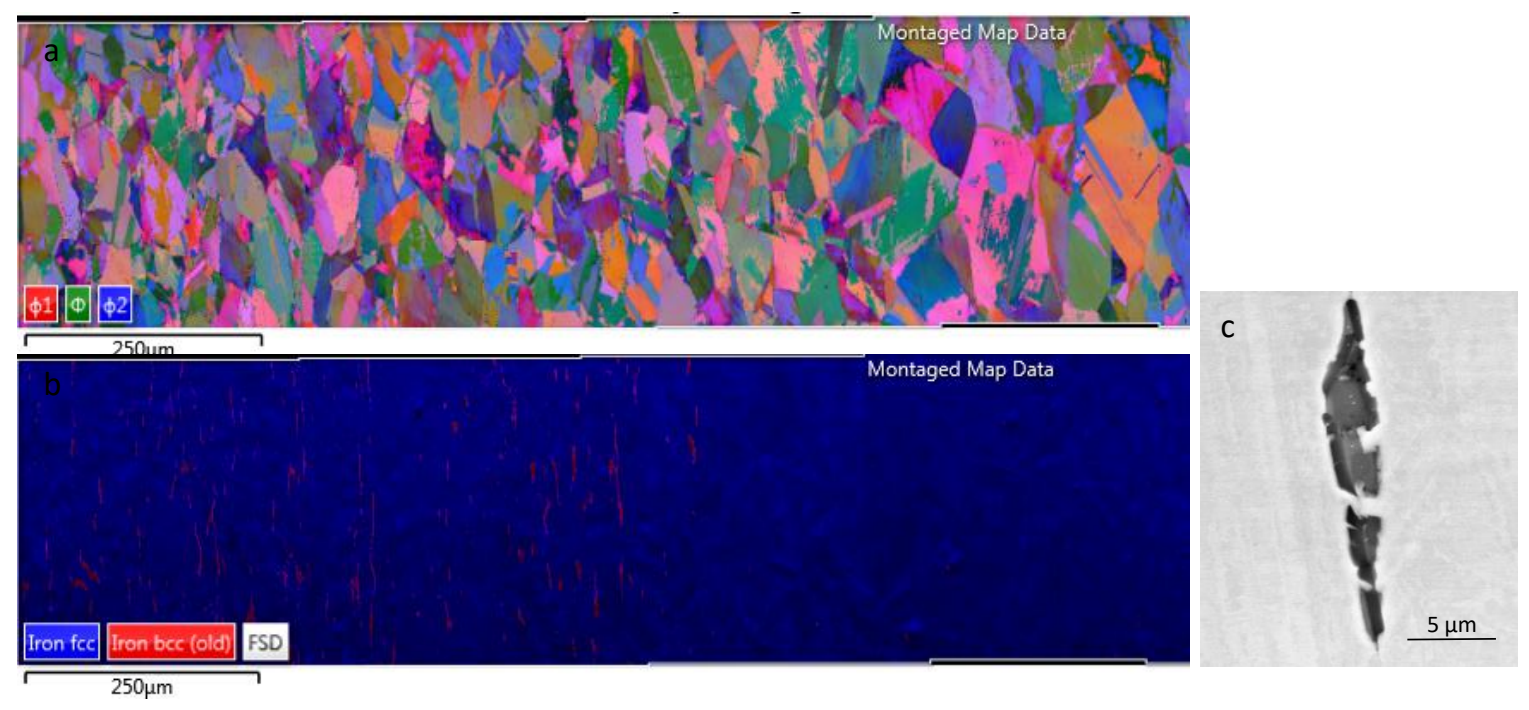

Figure 2 Baseline material characterization of the 304L forged used in this study. a) Euler colour map the grains present in both the typical microstructure. b) Phase map showing a segregation band which did not contain $\delta$ ferrite. c) Forward scatter detector electron image of an inclusion that possibly fractured during the material processing.

\subsection{Effect of inclusions on oxidation and cracking}

For SSRT tests that were conducted at a strain rate $1 \times 10^{-8} \mathrm{~s}^{-1}$ to a plastic deformation $3 \%$, the observed extent of cracking was relatively limited. SEM observation of the sample on the OPS surface indicated the presence of intragranular features that acted as initiation sites for transgranular (TG) cracking (Figure 3 left). It is likely that these intragranular features are associated with the dissolution of second phase inclusions [21] and the anodic activity cathodically protected the surrounded region which clearly underwent less oxidation (crystallite free regions).

An interesting feature noted at low magnification evaluation of the 600 grit surface was the presence of a banded structure formed in the oxide normal to the loading direction, in the central region of the sample (Figure 3 right). The bands are not associated with the presence of $\delta$-ferrite, since these bands are an order of magnitude larger than $\delta$-ferrite shown in Figure 2. Also, detailed microstructural characterization of the same material [21] showed that the $\delta$-ferrite oxidizes in a distinctly different manner to the austenite and forms a thinner oxide with few outer crystallites. However, from the images shown in Figure 3 right it is apparent that these bands underwent heavier oxidation (brighter bands pointed by the arrows in the main image) than the rest of the matrix.

Furthermore, these bands contained several features consistent with TG cracks, and were possibly associated with the dissolution of second phases. Like the observations of the OPS-prepared surface, these intragranular crack mouths had a region of low density oxide surrounding. 


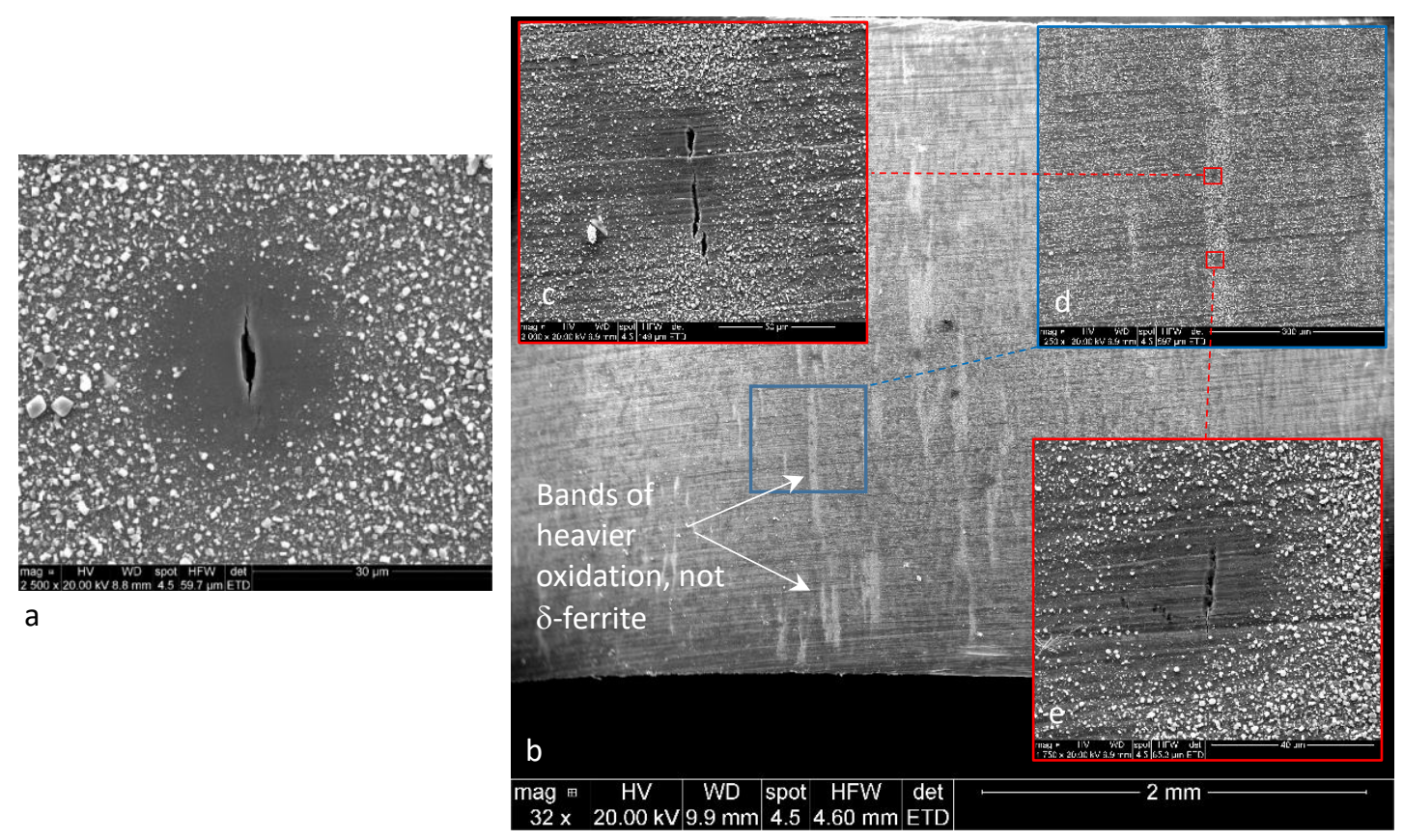

Figure 3 (a) SE images of an apparent "transgranular crack". It is possible that this feature was associated with the dissolution of a second phase/inclusion. (b) The oxidized 600 grit surface during SSRT showing a large scale banded structure (d) and within these bands several dissolved inclusions initiated TG cracking $(c, e)$. The sample plastically deformed by $3 \%$, at a strain rate of $1 \times 10^{-8} \mathrm{~s}^{-1}$ at $300^{\circ} \mathrm{C}$ in $3 \mathrm{ppm}$ dissolved hydrogen and 2 ppm of Li.

\subsection{Effect of strain and strain rate on the SCC initiation: Tapered Specimens}

A tapered sample with surfaces that were OPS polished prior to exposure was tested in the standard water chemistry $\left(300^{\circ} \mathrm{C}, 30 \mathrm{cc} / \mathrm{kg} \mathrm{H}_{2}\right.$ and $2 \mathrm{ppm}$ of Li as LiOH) and was strained for $650 \mathrm{~h}$ at constant extension rate that for a $12 \mathrm{~mm}$ parallel gauge length, would have been equivalent to $2 \times 10^{-8} \mathrm{~s}^{-1}$. Post-test dimensional measurements revealed that this sample had been elongated $350 \mu \mathrm{m}$. The advantage of using a tapered sample is that it is a multivariate experiment in which not only the strain but also the strain rate varies over the gauge length. Specifically, the strain and the strain rate are the highest in the smallest cross-section region and they decrease as the cross sectional area increases. The strain and strain rate distribution over the gauge length were calculated with an Excel macro using an idealized linearly elastic/linearly plastic constitutive law that best fit the tensile data at the test temperature. The results of this analysis are shown in Figure 4.

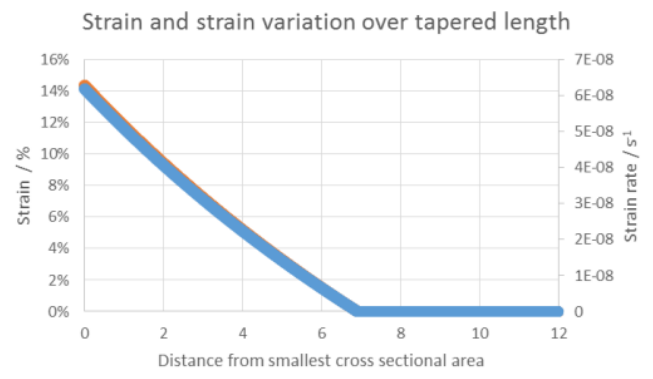

Figure 4 Calculated strain and strain rate variation over the gauge length of the tapered sample that was strained at an average value of $2 \times 10^{-8} \mathrm{~s}^{-1}$ over the $12 \mathrm{~mm}$ gauge length. 
As expected, the proportion of cracks was observed to decrease over the gauge area from the smallest section (highest strain and strain rate) to the largest section. Extensive cracking was present within the first two $\mathrm{mm}$ of the tapered gauge length, as reported in Figure 5. However, some isolated cracks were also detected up to $6 \mathrm{~mm}$ away from the narrowed part of the tapered gauge region. Moreover, the crack morphology was predominantly intergranular (IG), although some transgranular (TG) cracks were observed. Based on the strain and strain rate distribution in cracking behavior shown in Figure 5, it is predicted that the region that exhibited extensive cracking was strained between 9 and $14 \%$ at strain rate between be $4 \times 10^{-8}$ and $6 \times 10^{-8} 1 / \mathrm{s}$. Cracks up to $\sim 6 \mathrm{~mm}$ away from the narrowest point of the tapered sample were in a region corresponding to a strain less than $2 \%$ and a strain rate $\sim 10^{-8} \mathrm{~s}^{-1}$. Note that it is most likely that the controlling parameter is the plastic strain rather than the strain rate. In fact, it is expected that reducing the strain rate would increase the environmental interactions and so more SCC would be expected at lower strain rates [24].
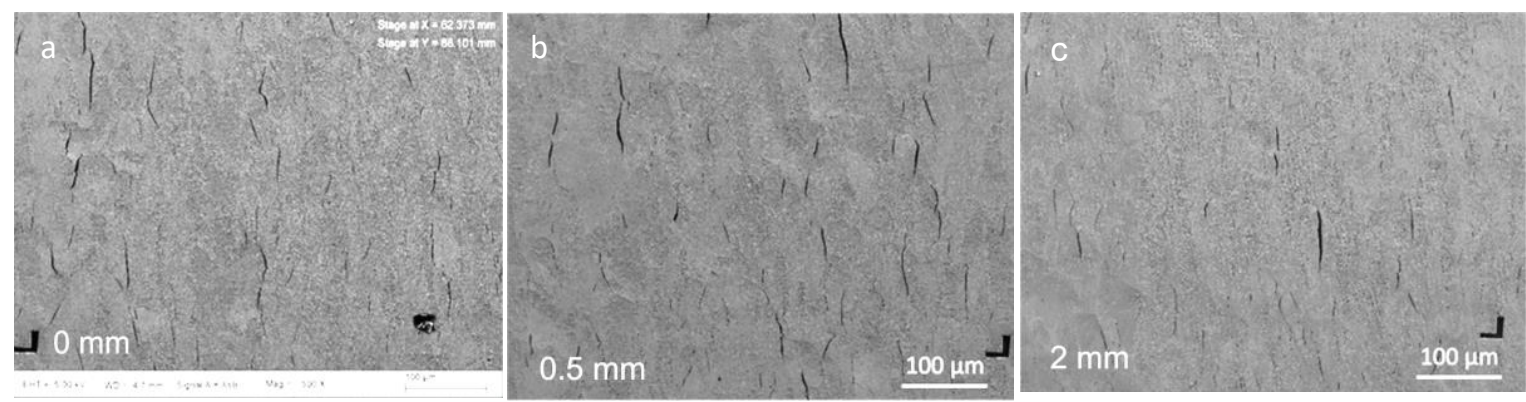

Figure 5 BSE images of the tapered sample tested at a constant extension (the average strain rate over 12 $\mathrm{mm}$ gauge was $2 \times 10^{-8} \mathrm{~s}^{-1}$ ) taken at different distance from (a) the smallest section, namely $0 \mathrm{~mm}$, (b) 0.5 $\mathrm{mm}$, and (c) $2 \mathrm{~mm}$.

A second tapered sample with one OPS-polished surface and one 600 grit surface was tested in similar condition but an equivalent strain rate of $10^{-7} \mathrm{~s}^{-1}$ and thus $5 \mathrm{x}$ faster than the previous sample. The purpose of this test was to identify the effect of strain rate on the SCC initiation susceptibility. Note that whilst Figure 4 was obtained for the sample strained at the strain of $2 \times 10^{-8} \mathrm{~s}^{-1}$, an identical curve would be expected for a sample strained to the same level at higher strain rate of $10^{-7} \mathrm{~s}^{-1}$. However, the predicted strain rates over the gauge length would be 5 times higher.

Post-test dimensional check revealed that this sample was strained by $400 \mu \mathrm{m}$. This sample tested at a faster strain rate sample showed more cracks, larger total crack length and average crack width than slower strain rate sample. An example of the cracking seen in the narrowest section is reported in Figure 6. However, it is important to bear in mind that this sample was plastically strained $50 \mu \mathrm{m}$ more and that this strain is mostly localized in the smallest gauge section area and contributing to about $1 \%$ higher plastic deformation.

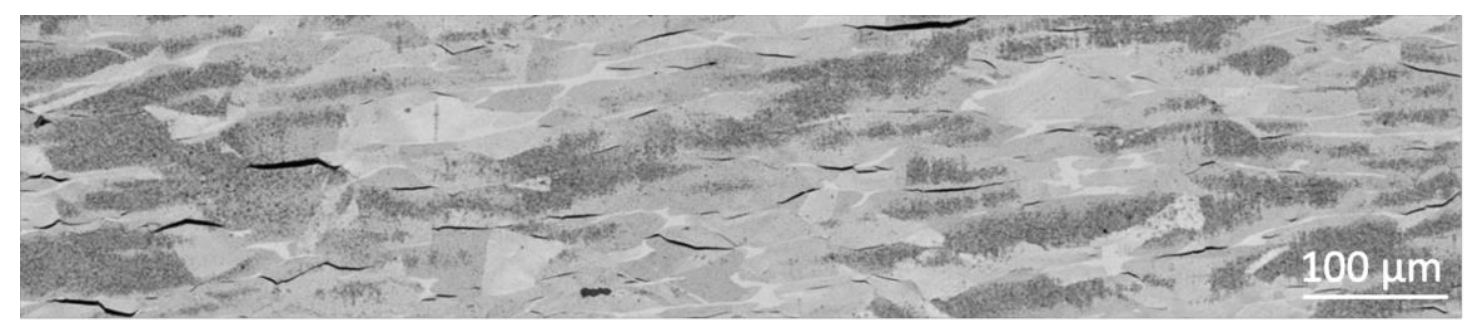




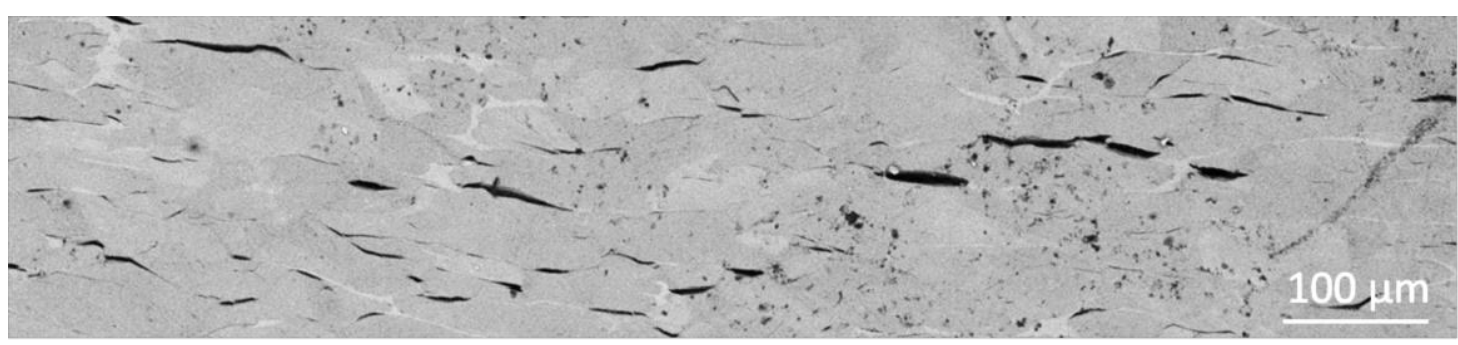

Figure 6 BSE images in the narrowest region of two tapered samples with OPS surface finish tested at (a) $\dot{\varepsilon}$ $=2 \times 10^{-8} \mathrm{~s}^{-1}, \Delta L \sim 350 \mu \mathrm{m}$, and $(b) \dot{\varepsilon}=1 \times 10^{-7} \mathrm{~s}^{-1}, \Delta L^{\sim} 400 \mu \mathrm{m}$. Note that these figures were rotated $90^{\circ}$ with respect to the others, i.e. the loading direction is vertical, whilst all the other figures the loading direction was horizontal.

Furthermore, the effects of surface preparation (OPS vs 600) appeared to play an important role as shown in Figure 7. Further results comparing the effect of surface preparation on oxide development have been reported by the present authors in a separate paper presented in this conference [21].

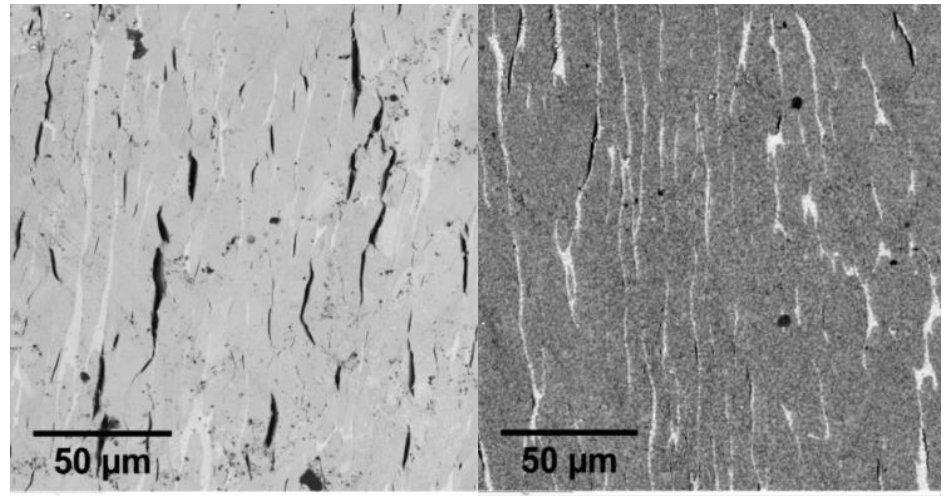

Figure 7 BSE images taken in the region with the lowest cross sectional area $(x=0 \mathrm{~mm})$ for the tapered sample tested at $10^{-7} \mathrm{~s}^{-1}$. Note the effect of surface preparation condition effect on extent of SCC: (a) OPS, and (b) 600 grit.

Overall, and irrespective of the strain rate, cracks were found to be mainly intergranular in nature for the OPS surface with some transgranular cracking present too (Figure $8 \mathrm{left}$ ). Furthermore the $\delta$ ferrite/austenite interface were shown to be very susceptible to SCC initiation, both for the OPS and the 600 grit surfaces (Figure 8).
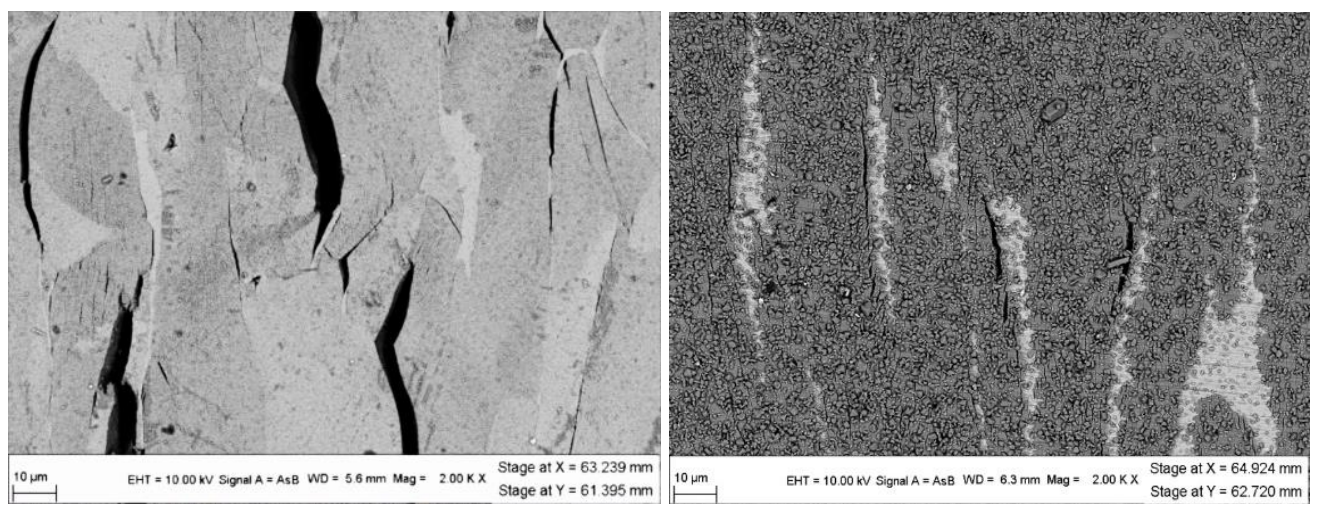

Figure 8 BSE images of tapered sample tested at strain rate of $1 \times 10^{-7} \mathrm{~s}^{-1}$ Left) OPS surface showing mixture of intergranular and transgranular as well as oxide cracking. $\delta$-ferrite interface cracking is also visible). 
Right) 600 grit surface showing mainly cracking at the interfaces between the $\delta$-ferrite and the matrix.

Transgranular oxide cracking is also visible.

\subsection{Effect of machining}

To examine the effect of machining on SCC, a chain of 5 samples with nominally the same dimensions but different surface machining parameters were tested under SSRT conditions. However, during the test only one sample failed whilst the others did not. Post-test examination of the samples showed that deformation was negligible for the non-failed 4 samples. It is therefore reasonable to assume that this failed sample experienced a strain rate $5 \mathrm{x}$ higher than the nominal $2 \times 10^{-8} \mathrm{~s}^{-1}$, i.e. $10^{-7} \mathrm{~s}^{-1}$, (or higher in the necked region). In hindsight, it is not surprising that one sample failed whilst the other were almost unstrained. In fact, $20 \%$ forged 304 has limited residual plasticity and relatively low work hardening (as typical for highly worked material). Consequently, if one sample starts yielding before the other (e.g. due to scatter in mechanical properties), this sample will be the weakest link and undergo preferential deformation. Further analyses were thus conducted on samples strained individually.

SEM characterisation was performed on the machined and OPS surfaces of the failed sample in the areas close to the necked region and along the gauge section where the deformation was more homogeneous. The results are shown in Figure 9. As expected, the crack density was greater in the necked region for both surface treatments as this region experienced a larger strain. On the machined surface the cracks were always TG in nature and associated with the machining marks, whilst away from the necked region little or no cracking was visible (Figure 9a). The morphology of the cracks in the necked region and the absence of cracks elsewhere were confirmed by microstructural evaluations of polished cross-section specimens presented in Figure $10 \mathrm{a}-\mathrm{b}$. In contrast to the machined surface, the cracks observed on the OPS polished surface were IG in nature and always perpendicular to the loading direction (Figure $9 \mathrm{~b}$ ). Furthermore, some cracks were also visible in the cross-section sample further away from the highly strained region (Figure 10 c-d). A difference in the crack depth was observed between the two surface finishes, with crack depths of $\sim 3 \mu \mathrm{m}$ and $60 \mu \mathrm{m}$ in the necked region of the machined surface (with no cracks away from this region) whereas the OPS polished surface exhibited crack depths ranging from $18 \mu \mathrm{m}$ to $95 \mu \mathrm{m}$. Overall, these results suggest that machining increased the SCC initiation resistance of the forged stainless steel.

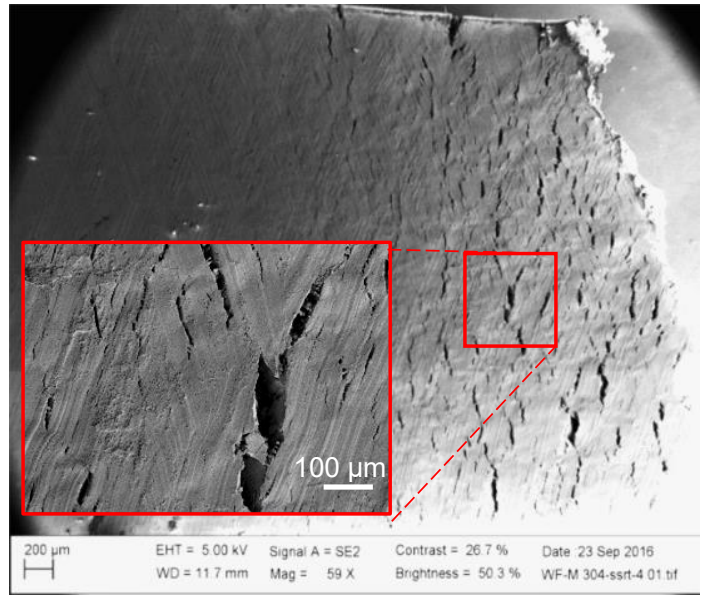

a)

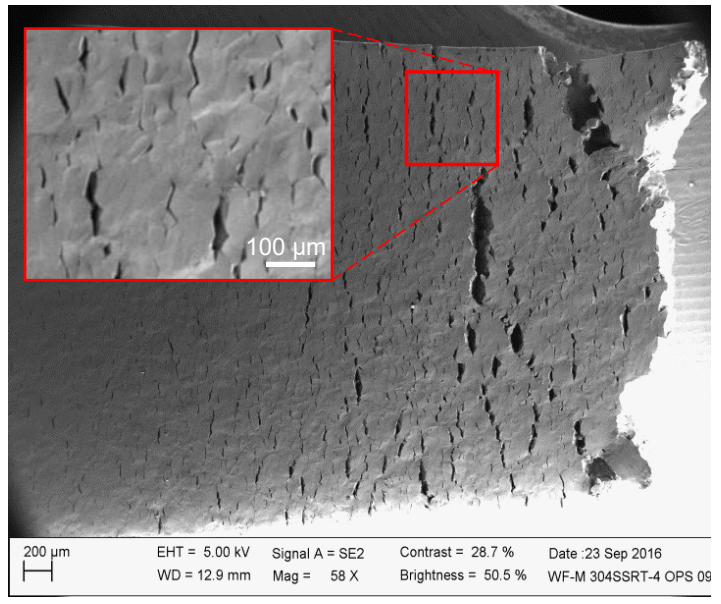

b)

Figure 9 Plan-view surface examination of the failed SSRT 304L sample. (a) Machined and (b) OPS surfaces. The necked region of the machined surface sample contained a high proportion of cracks along machining marks whereas the wider gauge section area contained few cracks. The OPS surface contained numerous intergranular cracks along the gauge section. 


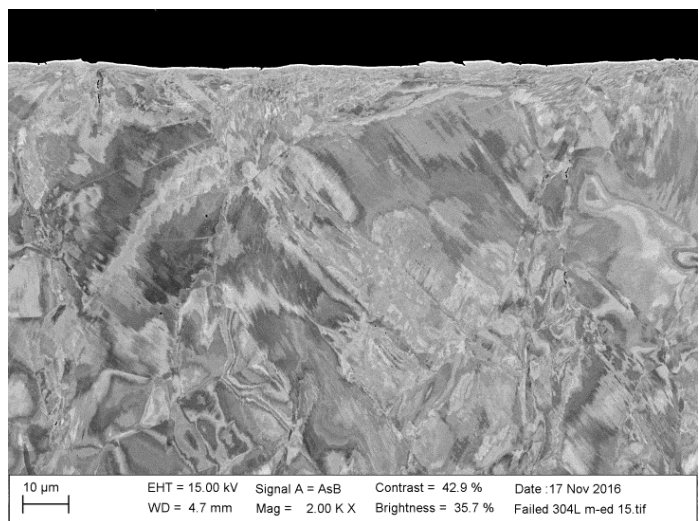

a)

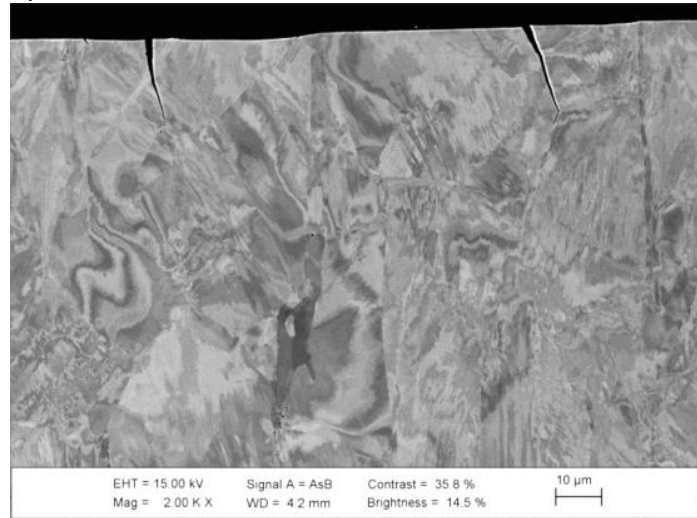

c)

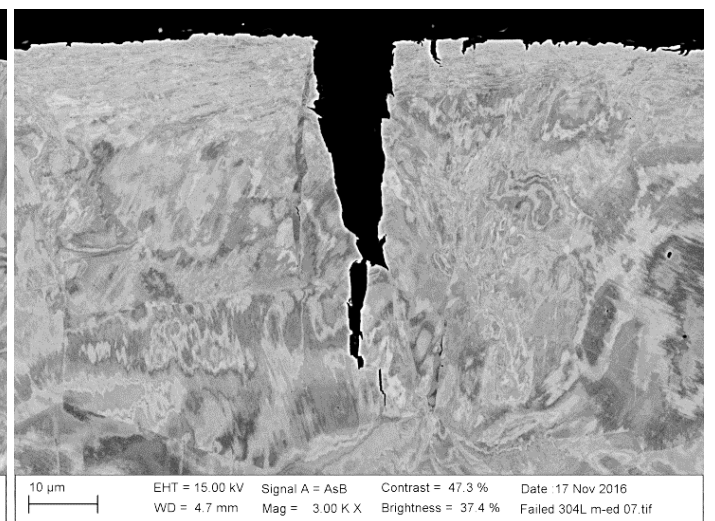

b)

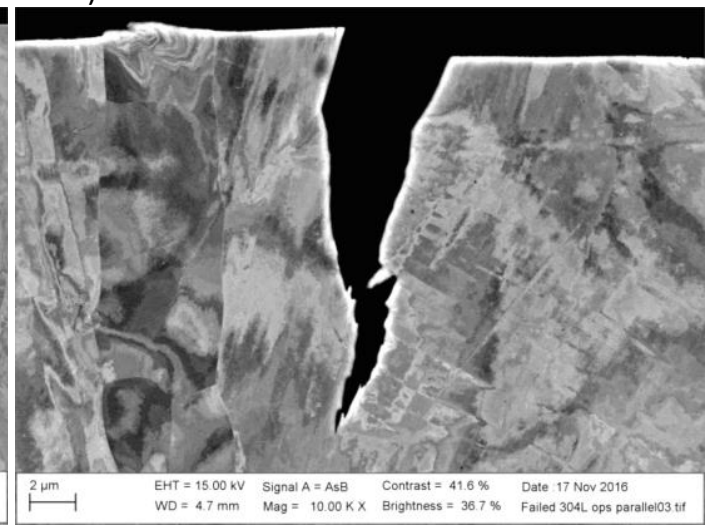

d)

Figure 10 BSE images obtained from the cross-section of the failed sample: (a)-(b) the machined surface, and (c)-(d) the OPS polished surface. TG cracks were visible on the machined surface in the necked region (b) whilst no cracks were observed in the gauge length away from the necked region (a). Conversely, on the OPS surface, the cracks extended beyond the necked region (c) and the cracks were predominantly IG. The cracks in the necked region (d) appeared to initiate intergranularly and to transition to transgranular most likely due to the higher localized strain in the latter stages of the test before failure occurred.

\subsection{Effect of carbon contamination on oxidation and crack initiation}

A tapered OPS-polished sample was characterized by EBSD over a relatively small area $100 \times 100 \mu \mathrm{m}^{2}$ prior to the slower strain rate test. Inadvertently, prolonged scanning by the electron beam over the region resulted in a carbon (C) contamination deposit on the specimen surface. The sample was subsequently cleaned and degreased with methanol. Post-test SEM characterisation revealed that this C-contaminated region was more heavily oxidized than the rest of the sample. Furthermore, whilst the sample exhibited significant intergranular cracking, the IG cracks did not appear to extend into the contaminated region and no evidence of SCC was found in this area (Figure 11). To assess whether the thicker oxide masked any evidence of SCC, serial sectioning using FIB (not reported in this paper for brevity) confirmed that the IG cracks did not propagate into the C-contaminated area.

In order to understand the reason for the effect of a C "layer" on SCC and oxidation, a coupon was polished with an OPS finish and plasma- cleaned to remove hydrocarbon contamination. The sample was then partially masked with a sheet of paper and C-coated using a conventional coater normally used for thin-film deposition. The nominal thickness of the carbon deposition was $20 \mathrm{~nm}$. The sample was then oxidized for 
$300 \mathrm{~h}$ under identical environmental conditions to those for the SSRT experiments. Figure 12 (a) shows an SEM image taken at the interface between plasma cleaned surface and $C$ coated region clearly shows a different oxidation behavior between the two surfaces (Figure 12 a). FIB cross sectional examinations confirmed the plan view examinations showing that on the $C$ coated region a significantly thicker inner oxide was present as well as a denser outer oxide than for the plasma cleaned surface.

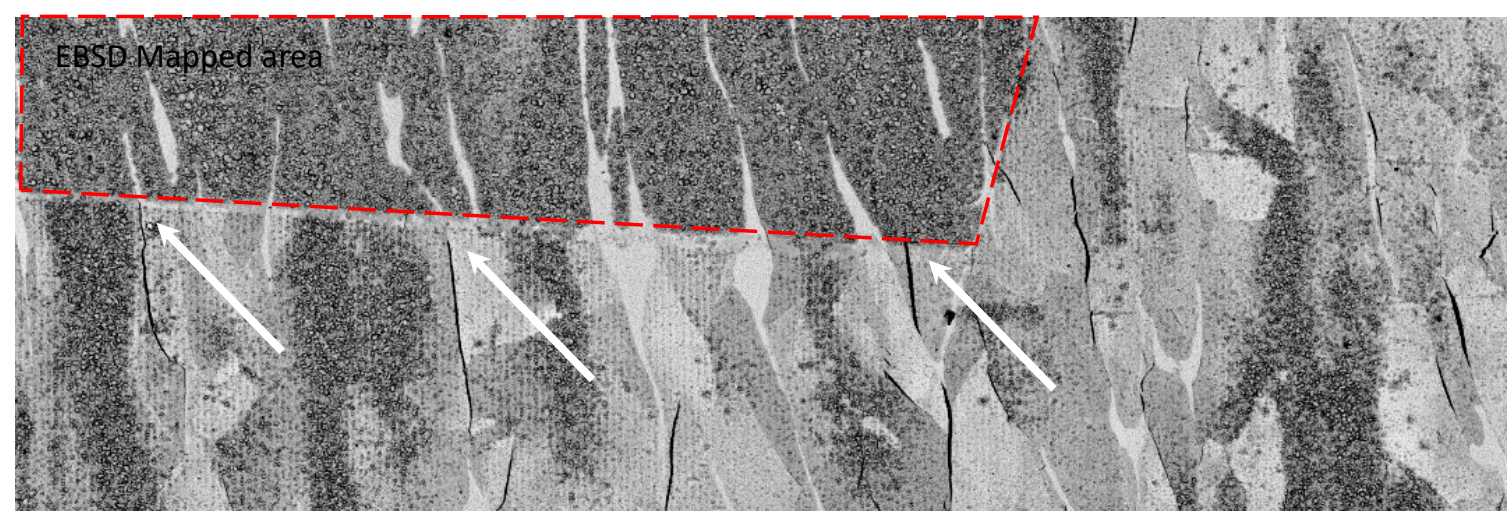

Figure 11 SEM image of the tapered sample tested at a strain rate $2 \times 10^{-8} \mathrm{~s}^{-1}$. IGSCC visible, however several cracks did not appear to extend into EBSD mapped (C-contaminated) area (outlined with a dotted red line).
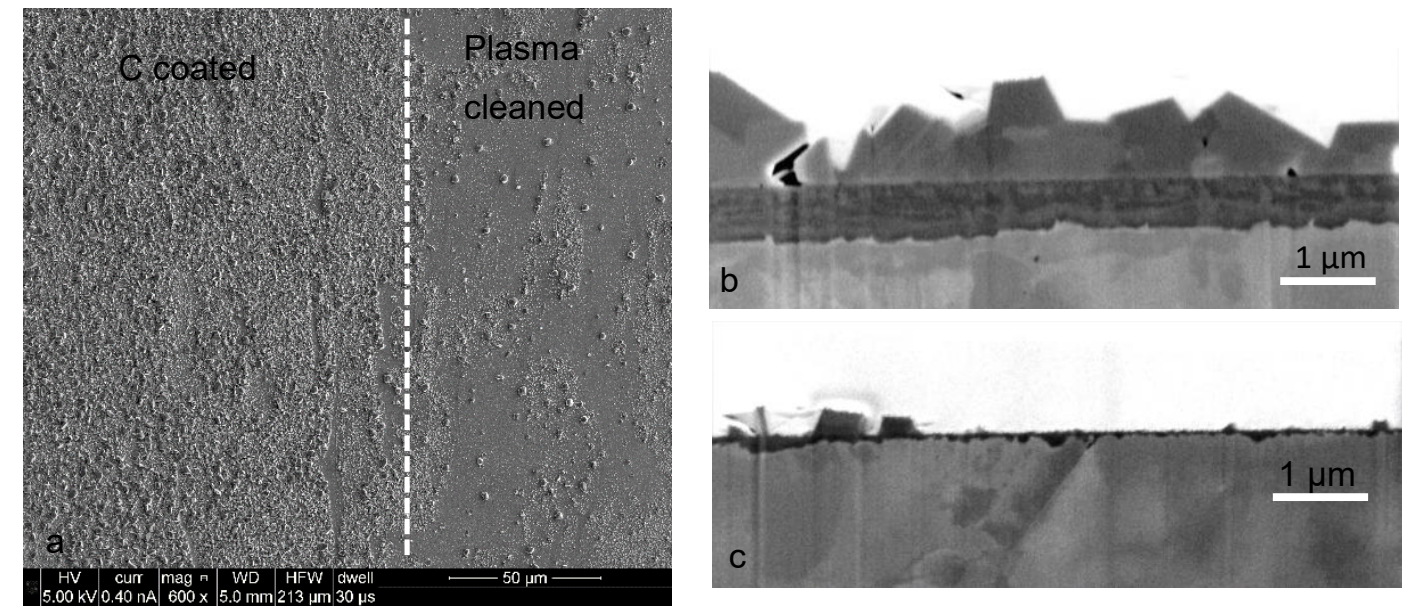

Figure 12 (a) SE image of the oxidized sample surface in which the right-half was OPS polished and plasma cleaned and the left-half was coated with a nominally $20 \mathrm{~nm}$ layer of $C$. The sample was oxidized in simulated primary water containing $2 \mathrm{ppm}$ of Li and $3 \mathrm{ppm}$ of $\mathrm{H}_{2}$ at $300^{\circ} \mathrm{C}$ for 300 hours. The FIB BSE images of cross-sections obtained the $C$-coated region and the plasma cleaned oxidized surfaces are shown in (b) and (c), respectively.

\section{Discussion}

In the present work accelerated SCC initiation behaviour was assessed using SSRT tests. Whilst it is recognised that the imposition of dynamic plastic straining is severe in the context of operating PWR plant, one of the immediate advantages is that the duration of the test is very short. Furthermore, recent work by Ritter et al. $[26,27]$ investigating the SCC initiation behavior of Alloy 182 showed that SSRT tests can provide 
results that are consistent with the outcomes obtained with more plant-relevant tests, such as constant load blunt notch compact tension (C(T)) tests. Most recently, Zhong et al. [28] provided more evidence that SSRT can be used as an acceleration methodology to obtain results that are relevant to primary water SCC in nuclear power plant.

IG and TG cracks that were associated with SCC occurred on all the SSRT samples tested, even on those samples that were tested at a relatively high strain rates. For instance, in the tapered sample extensive evidence of IGSCC was observed in the smallest section area of gauge section where the effective strain rate over the course of the experiment was predicted to be $\sim 3 \times 10^{-7} \mathrm{~s}^{-1}$. IGSCC also initiated on the OPS polished surfaces of one sample that eventually failed during the SSRT. In the necked region (i.e. where the strain is highest) SCC initiated intergranularly, and eventually transitioned to a transgranular morphology as the crack extended into the bulk of the sample. Results from tapered samples showed that cracks were observed in locations that were plastically strained by at least $2 \%$. This threshold value for SCC is not, however, a universal value since it is expected that this threshold value would decrease at lower strain rates $[26,27]$.

Crack initiation was also significantly promoted by the presence of the $\delta$-ferrite phase. From a plasticity point of view, and given that $\delta$-ferrite is body centered cubic whereas austenite is face centered cubic, it is not surprising that upon dynamic straining these interfaces undergo localized deformation. However, more work is required to understand whether, in the absence of dynamic straining (e.g. constant load and under more plant relevant conditions), these interfaces are also prominent sites for SCC initiation. SCC initiation was not always IG in nature but, depending on the surface preparation, it was also TG. This was the case for deformed surfaces (in particular for machined ones) and when surface breaking intermetallic inclusions were present.

The material used in this investigation was not homogeneous, and exhibited meso-scale segregation bands. Such bands, which have been reported to be $\delta$-ferrite free due to the locally elevated $\mathrm{Mn}$ and $\mathrm{Ni}$ content $[21,22]$ also had an increased density of complex multiphase inclusions that appeared to react during the test. These complex inclusions appeared to be capable of initiating intragranular defects. However, since they were mainly distributed intragranularly, none of the IGSCC appeared to directly initiate from with these inclusions. Nonetheless, it cannot be excluded that these intragranular defects can eventually propagate into more mature cracks. In fact, in the case of machined surfaces, the observed cracks always initiated transgranularly (i.e. in the machining marks) but eventually transitioned into intergranular cracks once a critical crack depth was reached [25].

In this work three different surface finishes (OPS finish, 600 grit and machining) were investigated and it was shown that the surface finish plays a major role on SCC initiation. A possibly counterintuitive finding was that the machined surfaces appeared to be the most resistant to SCC initiation for deformed (forged) Type 304 SS whilst the OPS surface finish was the most susceptible. These findings would thus suggest that higher surface deformation might be beneficial on the SCC initiation susceptibility. The deformed layer can have a higher diffusion of $\mathrm{Cr}$ to the surface which promotes a more continuous external oxide [29]. However, whilst this explanation is applicable for Ni base alloys such as Alloy 600 which are very susceptible to internal and intergranular oxidation [30], the oxide formed on austenitic stainless steel is significantly more homogeneous [31, 32]. A more likely explanation for the improved SCC initiation resistance of machined surface is that IG initiation is suppressed. In fact, the morphology of the observed cracks in the machined samples was always transgranular and associated with the machining marks, which can act as stress concentrators. Another reason for the greater propensity of TG cracking in deformed surfaces is related to the presence of an outer ultrafine-grained layer [25]. This layer, which forms following a complex thermomechanical processing during machining, has a greater proportion of grain boundaries that increase the diffusivity of the alloying elements, increases the oxidation rate of the outer layer [25] and prevents the localization of oxide formation over grain boundaries. 
An improved SCC initiation resistance was also noted for C-contaminated surfaces prior to the test. Carbon in solution could inhibit grain boundary sliding and cavitation while suppressing intergranular cracking during constant extension rate testing [34]. However, from the results shown in the present paper, $C$ also appears to enhance the formation of a thicker oxide (both inner and outer layer). Consequently, in the context of the precursor of SCC, the beneficial effect of $\mathrm{C}$ appears to be associated with the formation of a thicker oxide through which corrosion progresses faster than the development of localized mechanical deformation events before they can develop into cracks.

Overall, the effect of second phases, microstructure, surface finish and C contamination on oxidation and SCC initiation under SSRT was shown. Further testing under more plant relevant loading conditions should be conducted to validate the above finding.

\section{Conclusions}

In the present work, accelerated SCC initiation tests were performed using SSRT tests on parallel gauge and tapered samples, where these latter were employed for multivariate experiments where both the strain and the strain rate varied over the gauge area. The results of the work can be summarized as follows:

- In all the tests conducted type 304 stainless steel appeared to be very susceptible to IG SCC. The threshold strain for crack initiation for the current test conditions was around $2 \%$ and cracking propensity increased with strain, although the cracking behavior did not show a strong dependence with the strain rate.

- Surface preparation appeared to play a very important role in SCC initiation behavior whereby the machined surfaces were the least susceptible. The OPS polished surfaces were the most susceptible and 600 grit exhibited an intermediate behaviour.

- The crack morphology was mainly intergranular, although limited transgranular cracks were observed. The $\delta$-ferrite/austenite interfaces were shown to be very susceptible to SCC initiation for the OPS and the 600 grit surfaces. Furthermore, intragranular inclusions appeared to "dissolve" and act as initiation sites for transgranular cracking to occur.

- $\quad$ For the machined surfaces, the cracks were always TG in nature and associated with the machining marks. However, the test results revealed that these TG cracks can eventually transition into IG SCC once a critical depth is reached.

- It was shown that surface C contamination appears to mitigate SCC initiation by enhancing surface oxidation.

As a concluding remark, it is important to point out that more work is required to understand whether the above findings are also valid in the absence of dynamic straining (e.g. constant load and under more plant relevant conditions).

\section{Acknowledgements}

The authors would like to acknowledge the financial support of the New Nuclear Manufacturing (NNUMAN) program sponsored by EPSRC (grant EP/JO21172/1), Dr. Agostino Maurotto of the Nuclear Advanced Manufacturing Research Centre (University of Sheffield) for providing the machined plates.

\section{References}

[1] T. Couvant, L. Legras, C. Pokor, F. Vaillant, Y. Brechet, J. Boursier, P. Moulart, Investigations on the mechanisms of PWSCC of strain hardened austenitic stainless steels, in: $13^{\text {th }}$ International Conference on 
Environmental Degradation of Materials in Nuclear Power Systems, Whistler, BC (Canada), 2007, pp. 1923.

[2] S. Cissé, L. Laffont, B. Tanguy, M.-C. Lafont, E. Andrieu, Effect of surface preparation on the corrosion of austenitic stainless steel $304 \mathrm{~L}$ in high temperature steam and simulated PWR primary water, Corrosion Science, 56 (2012) 209-216.

[3] J. Gupta, J. Hure, B. Tanguy, L. Laffont, M.-C. Lafont, E. Andrieu, Evaluation of stress corrosion cracking of irradiated 304L stainless steel in PWR environment using heavy ion irradiation, Journal of Nuclear Materials, 476 (2016) 82-92.

[4] L. Tribouilloy, F. Vaillant, J. Olive, M. Puiggali, L. Legras, T. Couvant, J. Boursier, Y. Rouillon, C. Amzallag, Stress corrosion cracking on cold-worked austenitic stainless steels in PWR environment, Advances in Materials Science 7(2007) 11.

[5] O. Raquet, E. Herms, F. Vaillant, T. Couvant, J.-M. Boursier, SCC of cold-worked austenitic stainless steels in PWR conditions, in: T.R. Allen, P.J. King, L. Nelson (Eds.) $12^{\text {th }}$ International Symposium on Environmental Degradation of Materials in Nuclear Power Reactors, Salt Lake City, USA, 2005, pp. 10491058.

[6] T. Yonezawa, M. Watanabe, H. Atsushi, Effect of work hardened inner surface layers on stress corrosion cracking of type 316 stainless steel and TT alloy 690 in simulated PWR primary water, in: $17^{\text {th }}$ International Conference on Environmental Degradation of Materials in Nuclear Power Systems - Water Reactors, Canadian Nuclear Society, Ottawa, Ontario, Canada, 2015, pp. 496-513.

[7] P. Huguenin, J. Crepin, C. Duhamel, H. Proudhon, V. F., Initiation of stress corrosion cracking in prestained austenitic stainless steels exposed to primary water, in: $16^{\text {th }}$ International Conference on Environmental Degradation of Materials in Nuclear Power Systems - Water Reactors, NACE International, Asheville, North Carolina, USA, 2012, pp. 1414-1433.

[8] R. Staehle, Introduction to initiation, in: Workshop on Detection, Avoidance, Mechanisms, Modeling and Prediction of SCC Initiation in Water-Cooled Nuclear Reactor Plants, Beaune, France, 2008.

[9] Z. Lu, T. Shoji, F. Meng, Y. Qiu, T. Dan, H. Xue, Effects of water chemistry and loading conditions on stress corrosion cracking of cold-rolled 316NG stainless steel in high temperature water, Corrosion Science, 53 (2011) 247-262.

[10] J. Chen, Z. Lu, Q. Xiao, X. Ru, G. Han, Z. Chen, B. Zhou, T. Shoji, The effects of cold rolling orientation and water chemistry on stress corrosion cracking behavior of $316 \mathrm{~L}$ stainless steel in simulated PWR water environments, Journal of Nuclear Materials, 472 (2016) 1-12.

[11] D. Du, K. Chen, L. Yu, H. lu, L. Zhang, X. Shi, X. Xu, SCC crack growth rate of cold worked 316L stainless steel in PWR environment, Journal of Nuclear Materials, 456 (2015) 228-234.

[12] L. Zhang, J. Wang, Effect of temperature and loading mode on environmentally assisted crack growth of a forged 316L SS in oxygenated high-temperature water, Corrosion Science, 87 (2014) 278-287.

[13] S. Yaguchi, T. Yonezawa, Intergranular Stress Corrosion Cracking growth perpendicular to fatigue precracks in T-L oriented compact tension specimens in simulated Pressurized Water Reactor primary water, Corrosion Science, 86 (2014) 326-336.

[14] T. Couvant, F. Vaillant, J. Boursier, D. Delafosse, Effect of strain-path on stress corrosion cracking of AISI $304 \mathrm{~L}$ stainless steel in PWR primary environment at $360^{\circ} \mathrm{C}$, European federation of corrosion publications, 51 (2007) 87.

[15] G. Han, Z. Lu, X. Ru, J. Chen, Q. Xiao, Y. Tian, Improving the oxidation resistance of 316L stainless steel in simulated pressurized water reactor primary water by electropolishing treatment, Journal of Nuclear Materials, 467, Part 1 (2015) 194-204.

[16] Y. Han, J. Mei, Q. Peng, E.-H. Han, W. Ke, Effect of electropolishing on corrosion of Alloy 600 in high temperature water, Corrosion Science, 98 (2015) 72-80.

[17] Y. Han, J. Mei, Q. Peng, E.-H. Han, W. Ke, Effect of electropolishing on corrosion of nuclear grade 316L stainless steel in deaerated high temperature water, Corrosion Science, (2016).

[18] Y. Miura, Y. Miyahara, M. Sato, K. Kako, J.I. Tani, Behavior of Stress Corrosion Cracking for type 316L Stainless Steel with Controlled Distribution of Surface Work Hardened Layer in Simulated Boiling Water Reactors Environment, in: J.T. Busby, G. Ilevbare, P.L. Andersen (Eds.) $15^{\text {th }}$ International Conference on Environmental Degradation of Materials in Nuclear Power Systems-Water Reactors, Wiley Online Library, 2011, pp. 439-449. 
[19] Y. Miura, Y. Miyahara, K. Kako, M. Sato, Effects of Plastic Strain and Stress Distribution on SCC Initiation in High Temperature Water, in: CORROSION 2013, NACE International, 2013.

[20] T. Shoji, Progress in the mechanistic understanding of BWR SCC and its implication to the prediction of SCC growth behavior in plants, in: $11^{\text {th }}$ International Symposium on Environmental Degradation of Materials in Nuclear Power Systems-Water Reactors, NACE Stevenson Washington, USA, 2003, pp. 588598.

[21] G. Pimentel, D.R. Tice, V. Addepalli, K.J. Mottershead, M.G. Burke, F. Scenini, J. Lindsay, Y.L. Wang, S. Lozano-Perez, High-resolution characterisation of austenitic stainless steel in PWR environments: effect of strain and surface finish on crack initiation and propagation, in: $18^{\text {th }}$ International Conference on Environmental Degradation of Materials in Nuclear Power Systems - Water Reactors, TMS, Portland, Oregon, USA, 2017.

[22] D.R. Tice, V. Addepalli, K.J. Mottershead, M.G. Burke, F. Scenini, S. Lozano-Perez, G. Pimentel, Microstructural effects on stress corrosion initiation in austenitic stainless steel in PWR environments, in: $18^{\text {th }}$ International Conference on Environmental Degradation of Materials in Nuclear Power Systems Water Reactors, TMS, Portland, Oregon, USA, 2017.

[23] G. Bertali, F. Scenini, J. Lindsay, B. Winiarski, L. Zhong, M. Burke, G. Ilevbare, P. Andresen, M. Wright, Oxidation studies of Alloy 600 in low pressure hydrogenated steam, in: Proc. 16th Int. Conf. on

Environmental Degradation of Materials in Nuclear Power Systems-Water Reactors, eds. GO Ilevbare, PL Andresen, MD Wright, held August, 2013, pp. 11-15.

[24] N. Totsuka, Y. Nishikawa, Y. Kaneshima, Effect of strain rate on primary water stress corrosion cracking fracture mode and crack growth rate of nickel alloy and austenitic stainless steel, Corrosion, 61 (2005) 219-229.

[25] L. Chang, J. Duff, M.G. Burke, F. Scenini, SCC Initiation in the Machined Austenitic Stainless Steel 316L in Simulated PWR Primary Water, in: $18^{\text {th }}$ International Conference on Environmental Degradation of Materials in Nuclear Power Systems - Water Reactors, TMS, Portland, Oregon, USA, 2017.

[26] J. Bai, S. Ritter, H.P. Seifert, S. Virtanen, Using Tapered Specimens to Study the Effect of Hydrogen on SCC Initiation in Alloy 182 under BWR Conditions, in: EUROCORR 2016, Montpellier, France, 2016, pp. N. 50507.

[27] J. Bai, S. Ritter, H.P. Seifert, S. Virtanen, Stress corrosion cracking initiation and short crack growth behaviour in Alloy 182 weld metal under simulated boiling water reactor hydrogen water chemistry conditions, submitted to Corrosion Science, 2016.

[28] X. Zhong, S.C. Bali, T. Shoji, Accelerated test for evaluation of intergranular stress corrosion cracking initiation characteristics of non-sensitized 316 austenitic stainless steel in simulated pressure water reactor environment, Corrosion Science, 115 (2017) 106-117.

[29] F. Scenini, R.C. Newman, R.A. Cottis, R.J. Jacko, Effect of Surface Preparation on Intergranular Stress Corrosion Cracking of Alloy 600 in Hydrogenated Steam, CORROSION, 64 (2008) 824-835.

[30] C. Ostwald, H.J. Grabke, Initial oxidation and chromium diffusion. I. Effects of surface working on 920\% Cr steels, Corrosion Science, 46 (2004) 1113-1127.

[31] K. Kruska, S. Lozano-Perez, D.W. Saxey, T. Terachi, T. Yamada, G.D.W. Smith, Nanoscale characterisation of grain boundary oxidation in cold-worked stainless steels, Corrosion Science, 63 (2012) 225-233.

[32] S. Lozano-Perez, K. Kruska, I. Iyengar, T. Terachi, T. Yamada, The role of cold work and applied stress on surface oxidation of 304 stainless steel, Corrosion Science, 56 (2012) 78-85.

[33] V. Thaveeprungsriporn, T. Angeliu, D. Paraventi, J. Hertzberg, G. Was, Grain Boundary Deformation of $\mathrm{Ni}-\mathrm{Cr}-\mathrm{-Fe}-\mathrm{C}$ at $360 \mathrm{deg} \mathrm{C}$, in: $6^{\text {th }}$ International Symposium on Environmental Degradation of Materials in Nuclear Power Systems--Water Reactors, 1993, pp. 721-727.

[34] J. Hertzberg, G. Was, The effect of carbon on grain boundary diffusivity in Ni-16Cr-9Fe alloys, Scripta Metallurgica et Materialia, 33 (1995) 1193-1199. 